\title{
Captopril Renal Scintigraphy in Screening and Diagnosis of Renal Artery Stenosis - A Prospective Study
}

\author{
Rauniyar RK ${ }^{1}$, Bal CS ${ }^{3}$, Kumar $R^{3}$, Srivastava $\mathrm{DN}^{2}$, Dash $\mathrm{SC}^{4}$, Gupta $\mathrm{A}^{1}$, Berry $\mathrm{M}^{2}$
}

${ }^{1}$ Department of Radiodiagnosis, BPKIHS, Dharan, Nepal, ${ }^{2}$ Department of Radiodiagnosis, ${ }^{3}$ Department of Nuclear Medicine, ${ }^{4}$ Department of Nephrology, AIIMS, New Delhi, India

\begin{abstract}
The present study was carried out to assess the role of Tc99m-DTPA captopril renal scintigraphy in screening and diagnosing of patients with renal artery stenosis. Materials and Methods: A total of 26 hypertensive patients with a clinical suspicion of RAS underwent baseline and captopril scintigraphy using 259-370 MBq (7-10mCi) of Tc99m-DTPA. The captopril scintigraphy was done after oral dose of $50 \mathrm{mg}$ of captopril with in three baseline study. DSA was done in all patients irrespective of scintigraphy results due to high clinical suspicion of RAS. Results: Of 26 patients, 18 had renal artery stenosis (10 unilateral, 8 bilateral), making a total of 26 involved RA on DSA. Of these 26 involved RA, 16 were stenosis $>60 \%, 2$ were stenosed $<60 \%$ while 8 were completely occluded. Of the sixteen RA with stenosis $>60 \%$, only 12 were detected by captopril scintigraphy (Sensitivity-75\%). Eight kidneys with complete occlusion, 6 were non-functioning and 2 were poorly functioning $(<20 \%)$ on scintigraphy. Among 27 normal RA, (25 normal and two $<60 \%$ stenosis) only 19 were negative on scintigraphy (specificity-70\%). Two kidneys with less than $60 \%$ stenosis were positive on scintigraphy. The overall accuracy of captopril DTPA scintiography was found to be $72.1 \%$ with PPV and NVP of $66.7 \%$ and $82.6 \%$ respectively. Two patients with accessory RA were not picked up on captopril scintigraphy. Conclusion: Tc99m-DTPA captopril scintigraphy has average sensitivity and specificity. The effectiveness of captopril scintigraphy in diagnosis of completely occuluded RA, accessory RAS and RAS in poorly functioning kidney is poor, therefore this test can not be considered as screening test for RVH.
\end{abstract}

Keywords: Captropril Renal Scintigraphy, Tc99m-DTPA, Accessory renal artery stenosis

\section{Introduction}

Renovascular hypertension (RVH) is a potentially curable hypertension, most commonly caused by renal artery stenosis (RAS). ${ }^{1}$ Therefore, there is a need for suitable screening modalities. Digital substraction angiography (DSA) is gold

Correspondence to: Dr. R. K. Rauniyar, Professor and Head, Department of Radiodiagnosis and Imaging, BPKIHS, Dharan, Nepal

E-mail: rauniyar99@yahoo.com 
standard in the diagnosis of RAS, but due to invasiveness and high cost, it is not suitable for screening. ${ }^{1} \quad$ Various investigations including color Doppler has been tried as screening test with variable success rate ${ }^{1-4}$. Role of magnetic resonance angiography (MRA) in detecting RAS is limited to osteal and proximal stenosis without establishment of physiological significance. ${ }^{5}$ Further, recent study have shown that MRA has good sensitivity and specificity in diagnosis of RAS but high cost and limited availability is limited to be considered as screening test. ${ }^{6}$ Computed Tomography (CT) angiography and gadolinium enhanced three dimensional MRA seems to be preferred in patients of suspected RAS. However, due to limited published data in literature, further research is recommended. ${ }^{7}$ Renal scintigraphy with Tc99m-diethylenetriamine pentaacetate (DTPA) without captropil had poor sensitivity and specificity in detecting RAS.

However, with combination of captropil, an Angiotensin Converting Engyme (ACE) inhibitor, sensitivity and specificity has been markedly improved. ${ }^{1}$ A large list of studies is available in the literature regarding the role of renal scintigraphy with Tc99m-DTPA and with other radioactive pharmaceutical agents, with or without captopril in screening and diagnosing patients with RAS with variable and concontrdictory results. ${ }^{8-20}$ The exact role and accuracy of this investigation in screening of the patients with RAS is not established. With rapid advance in technique and radiotracer in nuclear medicine, there is need to find a suitable screening method for diagnosis of RAS. This study has been under taken to assess the role of renal scintigraphy using Tc99m-DTPA with and without captopril in screening and diagnosis of RAS considering DSA as gold standard. A through review of literature has also been discussed in the study.

\section{Materials and methods}

A total of 26 hypertensive adult patients, 12 male and 14 female were included in the study on the basis of high index of clinical suspection of having RAS. All hypertensive patients were evaluated with renal scintigraphy and DSA within two weeks of each other after obtaining informed consent. Both baseline and captopril Tc99m-TDPA renal scintigraphy were conducted on different days but in with in three days of each other. The antihypertensive medications were continued except ACE inhibitors and diuretics which were stopped 48-72 hrs before the procedure. Patients were instructed to drink $500 \mathrm{ml}$ of water prior to study for proper hydration.

A large field of view Gamma camera (Siemens, Orbitor) fitted with a general purpose parallel hole, low gamma ray energy collimator was used. The Gamma camera was peaked at $140 \mathrm{KeV}$ energy for technetium with a $20 \%$ window. The study was conducted with patient lying supine on a couch and the camera positioned posteriorly keeping the renal area around the centre of the detector. Standard protocol was followed in all studies. Baseline studies were acquired after intravenous injection of 259-370 MBq (7-10mCi) of Tc99m-DTPA. Scintigraphic data was recorded in frame mode (Total frames $=120, \quad$ Time/frame $=16 \mathrm{sec}$ ) starting immediately after injection. From raw data the renogram curve was generated by the computer.

The same protocol was repeated in the second sitting, 60 minutes after the oral 
administration of $50 \mathrm{mg}$ captopril. Blood pressure was measured prior to the administration of captopril and at 20 minutes intervals thereafter until the end of the study.

DSA was done in all 26 patients irrespective of scintigraphy results. Using Seldinger technique $6 \mathrm{~F}$ arterial sheath was introduced through femoral artery. Flush aortogram was obtained using pigtail catheter (4-5 F). Then selective catheterization of each renal artery (RA) was done using 4-5 F renal catheter and each of them were evaluated selectively. More than $60 \%$ diameter reduction was considered as significant stenosis which was calculated from the minimal residual lumen diameter and the average diameter in the normal position of RA on DSA.

The criteria for positive test on captopril Tc99m-DTPA scintigraphy for significant RAS as compared to base line scintigraphy were, delayed uptake, delayed peak activity more than 5 minutes, fall in glomerular filteration rate (GFR) more than $5 \%$ and slowing of the excretory phase more than $20 \%$. The results of captopril renal scintigraphy and DSA were interpreted by two different physicians without the knowledge of results of other investigation. The sensitivity, specificity, positive predictive value (PPV) and negative predictive value (NPV) and over all accuracy was calculated considering DSA as gold standard.

\section{Results}

Of 26 hypertensive patients, RA involvement was present in 18 on DSA. Of the 18 patients positive for RA stenosis, 10 had unilateral and 8 had bilateral involvement making a total of 26 involved RA, 16 were stenosed more than $60 \%, 2$ were stenosed less than $60 \%$ while 8 were completely occluded $(100 \%)$.

Out of 16 RA which had stenosis of more than 60\%, captopril scintigraphy was positive for RAS in only 12, making a sensitivity of $75 \%$ (Fig 1). Among 27 normal RA (25 normal and two $<60 \%$ stenosis) only 19 were correctly identified, making a specificity of $70 \%$ (Figure-2). Two kidneys with less than $60 \%$ stenosis of RA on DSA were picked up as having significant RAS on DTPA scintigraphy. The overall accuracy of captopril DTPA scintigraphy was found to be $72.1 \%$. The PPV of DTPA scintigraphy was found to be $66.7 \%$ and NPV to be $82.6 \%$.

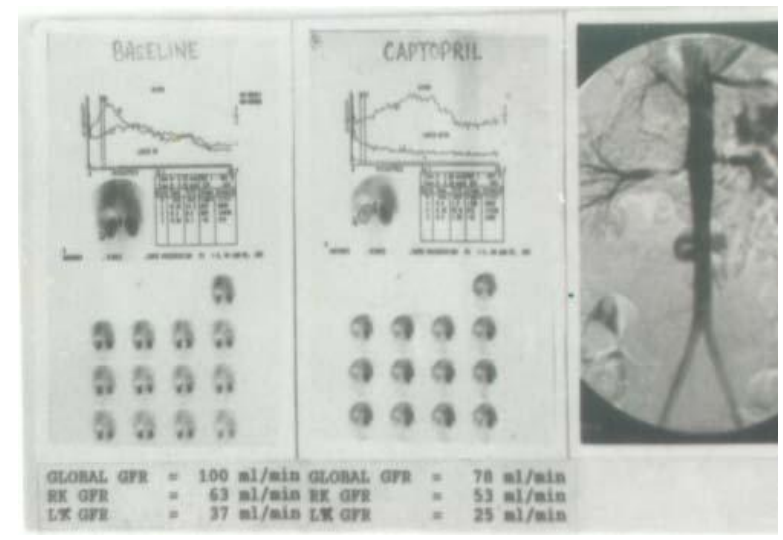

Fig 1: Pre and Post Captopril DTPA Scintigraphy suggesting right RAS confirmed on DSA.

Among 8 RA, which were completely occluded on DSA, 6 were non-visualized (non-functioning) and 2 were seen as poorly functioning kidneys $(<20 \%)$ on scintigraphy. Captopril scintigraphy was false negative in 4 kidneys. Among these 4, two kidneys had stenosis of accessory RA with normal main RA and one kidney was poorly functioning. 
Table 1: Captopril Renal Scintigraphy studies in the diagnosis of renal arterystenosis

\begin{tabular}{|c|c|c|}
\hline Author & Radiopharmaceutical & Results \\
\hline Maxwell MH(1975) ${ }^{8}$ & I131-Iodohippurate & $\begin{array}{l}25 \% \text { False positive, } \\
24 \% \text { False negative }\end{array}$ \\
\hline Chiarini C et al (1982) ${ }^{9}$ & Captopril Tc99m-DTPA & Sesitivity-90\%, specificity-91\% \\
\hline Gross ML et al (1985) ${ }^{10}$ & Tc99m-DTPA/I131 OIH & DTPA more superior \\
\hline Geyskes et al (1987) ${ }^{11}$ & Captopril Tc99m-DTPA & Sensitivity- $80 \%$, Specificity-100\% \\
\hline Nally JV et al (1988) ${ }^{12}$ & Captopril Tc99m-DTPA & Sensitivity-100\%, Specificity-100\% \\
\hline Safakianakis GN (1989) ${ }^{13}$ & Captopril-131-OIH & Sensitivity-100\%, Specificity-100\% \\
\hline Svetkey LP et al (1989) ${ }^{14}$ & $\begin{array}{l}\text { Captopril Tc99m-DTPA } \\
\text { Captopril-131-OIH }\end{array}$ & $\begin{array}{l}\text { Sensitivity-91\%, Specificity-50\% } \\
\text { Sensitivity-80\%, Specificity- } 42 \%\end{array}$ \\
\hline Charles C et al (1990) $)^{15}$ & $\begin{array}{l}\text { Captopril Tc99m-DTPA } \\
\text { Without Captoril }\end{array}$ & $\begin{array}{l}\text { Sensitivity-91\%, Specificity-93\% } \\
\text { Sensitivity-43-68\% }\end{array}$ \\
\hline Kakizaki H et al (1992) ${ }^{16}$ & Captopril Tc99m-DTPA & Sensitivity-86\%, Specificity-100\% \\
\hline Man SJ etv al (1992) $)^{17}$ & Captopril Tc99m-DTPA & Sensitivity-93\%, Specificity-95\% \\
\hline Elliott WJ et al $(1993)^{18}$ & Captopril renography & Sensitivity-92\%, Specificity- $80 \%$ \\
\hline Orellana $P$ et al $(1993)^{19}$ & Captopril Tc99m-DTPA & Sensitivity-60.9\%, Specificity- $89.2 \%$ \\
\hline Dev HM et al $(1993)^{20}$ & Captopril Tc99m-DTPA & $\begin{array}{l}\text { Sensitivity-85\%, } \\
\text { Specificity- } 84 \%\end{array}$ \\
\hline
\end{tabular}

\section{Discussion}

Captopril renal scintigraphy is used for detection of RAS and to assess angiotensin dependent $\mathrm{RVH}$ and helps in prognosticating the patients out comes. It is ideal tool for renal functional study. In past, renal scintigraphy has been tried using various agents for diagnosis of RAS. Majid M et al in 1983 used Captopril, an ACE inhibitor, to improve diagnostic accurancy of renal scintigraphy in renovascular hypertention $(\mathrm{RVH}){ }^{21}$ Wenting G S et al (1984) used captopril renal scintigraphy in hypertensive patients and observed that all patient with normal RA had unchanged Tc99m-DTPA uptake after captopril administraton while patient with RAS had decreased uptake. ${ }^{22}$ Miyamori I et al (1986) using post captopril Tc99m-DTPA showed that reduction in GFR following captopril in stenotic artery was due to reduction of angiotensin-II mediated efferent arteriolar constriction. ${ }^{23}$ Sfakianakis NG et al (1987) compared 131 I-iodohippurate $(\mathrm{OIH})$ and Tc99m-DTPA Scintigraphy in same patient and showed that scintigraphy with OIH scintigraphy with OIH appears to be more sensitive and specific than DTPA and concluded that OIH scintigraphy with captopril may provide a rapid and sensitive screening test for $\mathrm{RVH}^{24}$ Fommei E at al (1987) reported positive captopril induced changes in Tc99m-DTPA scintigraphy which predicted patients who can be cured by revascularization or percutaneous transfemoral renal angioplasty (PTRA). ${ }^{25}$ Mann S J et al (1991) compared usefulness of $131 \mathrm{I}-\mathrm{OIH}$ scintigraphy to be more accurate than Tc99m-DTPA. ${ }^{26}$ Dondi $M$ et al (1992) evaluated prognostic value of 
a

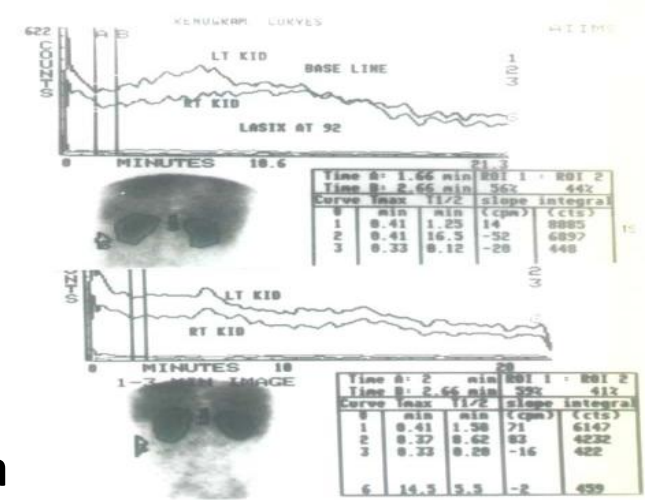

b

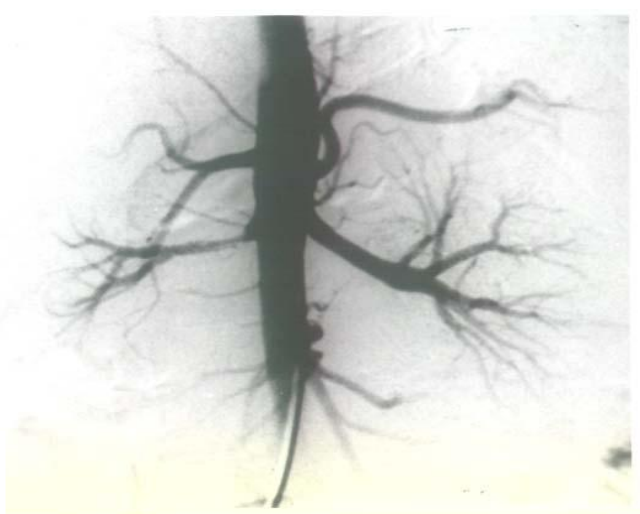

Fig 2a: Pre and Post Captopril DTPA Scintigraphy suggesting false positive diagnosis of bilateral RAS as DSA (2b) showing normal left RA and less than $60 \%$ stenosis of right RA.

captopril renal scintigraphy in RVH and showed that positive preoperative renal scintigraphy in strong predictor of hypertension curability of revascularization. ${ }^{27}$

As far as ACE inhibitor scintigraphy is concerned there are many studies available which are shown in Table 1, but yet there is no consensus on scintigraphy protocol including radiopharmaceutical, sequence of studies, ACE inhibitors, their dose and specific criteria. ${ }^{8-20}$ Nally JV et al achieved the sensitivity and specificity of $100 \%$ and their criteria for positive test were decrease in maximum activity, delayed uptake, widening of peak activity and slowing the excretory phase. ${ }^{12}$ But on contrary, Kumar $r$ et al and Orellana $\mathrm{P}$ et al showed lower sensitivity of $44.4 \%$ and $60.9 \%$ respectively. ${ }^{19,28}$ ACE inhibitor scintigraphy with Tc99m-DTPA used in several centres found a sensitivity and specificity ranging from $75-84 \%{ }^{29}$ Nally JP in there recent report has highlighted that captopril renography alone is a safe and effective means of noninvasively screening hypertensive patients. A positive study in an appropriately screened hypertensive patients with preserved renal function suggests renovascular diseases with sensitivity and specificity in excess of $90 \% .{ }^{30}$

In the present study, by the criteria for positive test on catopril 99mTc-DTPA scintigraphy as mentioned earlier, we achieved a sensitivity of $75 \%$ and specificity of $70 \%$ with overall accuracy of $72.1 \%$. Six patients were false positive on captopril renal scintiography. Of these 6, two had less than $60 \%$ stenosis and four had normal RA on DSA. Arterial stenosis demonstrated on DSA in these two patients may be significantly stenosed to produce angiotensin dependent hypertension as mere localization of stenosis on DSA may not establish physiological significance of stenosis as $45 \%$ normotensive has RAS. $^{31}$ Probably renal scintigraphy increase the accuracy in the present study. If we consider these two patients as positive for RAS, then sensitivity of captopril

Scintigraphy improves $77.7 \%$ from $75 \%$ and specificity improves $76 \%$ from $70 \%$. However, we could not flow these patient to see that the hypertension was cured after revascularization or PTRA to validate the the significance of the captoprol scintigraphy in $<60 \%$ RAS. 
Among at RA which was completely occuluded on DSA, only six were correctly identified as nonfunctioning (nonvisualised) kidney, while two were properly functioning. This is probably due to collaterals vessels supplying the occluded kidneys then DTPA scintigraphy has failed to identify two occluded kidneys. Poorly functioning kidneys on DTPA scintigraphy may suggest very tight or near total occlusion.

On captopril scintigraphy, there were 4 false negative diagnosis. In two cases there were accessory RA stenosis with normal main RA which were not picked up on scintigraphy. Therefore, there is need for regional scintigraphy analysis in all suspected cases of $\mathrm{RVH}$ in order to improve the chance of detecting accessory RAS. Ergum et al were able to detect accessory RAS by analyzing the kidney in multiple regions. ${ }^{32}$ Further, RAS in poorly functioning kidney was missed in renal scintigraphy. Therefore there is need for identifying suitable radiotracer to identify RAS in poorly functioning kidneys. The pitfalls of Captopril scintigraphy include patients with dilated renal pelvis, urinary obstruction, borderline or very severe RAS, bilateral disease and RHV associated with renal insufficiency or failure. ${ }^{26,33}$ In the present study we share experience.

In conclusion, captopril Tc99m-DTPA renal scintigraphy has average sensitivity and specificity. Further, its effectiveness in diagnosis of accessory RAS and RAS in poorly functioning kidney is doubtful therefore, this test can not be considered as screening test for RVH.

\section{References}

1. Dunnick NR, Sfakianakis GN. Screening for renovascular hypertension. Radiol Clin North Am. 1991; 29:497-510.

2. Berland LL, Koslin DB, Routh WD,Keller FS. Renal artery stenosis:prospective evalution of diagnosis with colar duplex US compared with angiography. Radiology.1990; 174:421-423.

3. Desberg AL,Paushter DM,Lammert GK, Hale JC, Troy RB, Novick AC. et al. Renal artery stenosis colar Doppler flow imaging. Radiology.1990; 177:749-753.

4. Stavros AT, Parker SH, Yakes WF, Chantelosis AE, Burke BJ, Meyers PR et al. Segmental stenosis of renal artery: pattern recognition of tardus and parvus abnormalities with duplex sonography. Radiology.1992; 184:487-492.

5. Loubeyre P, Revel D, Douek P, Deligenette A, Baldy C, Genin G, et al. screening patients for renal artery stenosis: value of three dimensional time of flight MR angiography. AJR Am J Roentgenol. 1994; 1035-1039.

6. Chan YL, Leung CB, Yu SC, Yeung DK, LI PK. Comparision of non-breath hold high resolution gadolinium enhanced MRA with Dgital substraction angiography inevulation on allograftr renal artery srenosis. Clin Radiol. 2001; $56: 127-132$.

7. Vasbinder GB, Nelemans PJ, Kessels AG, Kroon AA, de Leeuw PW, Engelshoven JM. Diagnostic test for renal artery stenosis in patients suspected of having renovascular hypertension-a 
metaanalysis. Ann Intern Med. 2001; 18; 135:401-11.

8. Maxwell MH: Cooperative study of having renovascular hypertension current status. Kidney Int Soppl. 1975; 8:S153160.

9. Chiarini C, Esposti ED, Losinno F, Monetti N, Pavliva P, et al. Renal scintigraphy versus renal vein rennin activity for identifying and treating renovascular hypertension. Nephron. 1982; 32:8-13.

10. Gross M L, Nally J V, Windham J P. improved computer assisted nuclear imaging in renal vascular hypertension. J Clin Hyperrens 1985; 4:326-335.

11. Geyskes GG, Oei HY, Puylaer CB, Mess EJ. Rebnovascular hypertension identified by captopril induced changes in the renogram. Hypertension. 1987; 9:451-458.

12. Nally JV Jr, Gupta BK, Clarke HS Jr, Higgins JTJr, Potvin WJ, Gross ML. captopril renography for the detection of renovascular hypertension. Cleve Clin J Med. 1988; 55:311-318.

13. Sfakianakis GN, Jaffe DJ, Bourgoignie JJ, Coptopril scintigraphy in the diagnosis of renovascular hypertension. Kidney Int Suppl. 1988; 25 :S142-144.

14. Svetrkey LP, Himmelstein SI, Dunnick NR, Wilkinson RH Jr, Borllinger RR, McCann RL, et al. prospective analysis of strategies for diagnosing renovascular hypertension. Hypertension. 1989; 14247-57.

15. Chen CC, Hoffer PB, Vahjen G Gottscalk A,Koster K, Zubal IG, Et al patients at high risk for renal scintigraphy analysis with risk for renal artery stenosis: A simple method of renal scintigraphy analysis with Tc99m-DTPA and captopril. Radiology. 1990; 176:365370 .

16. Kakizaki H, Togashi M, Kurisu K, Koyanagi T, Itoh K. Single dose captopril -test and captopril renal scintigraphy in the evaluation of renovascular hypertension. Nippon Hinyokikaw Gakkai Zasshi. 1992; 83:1668-1676.

17. Mann SJ, Pickering TG: Detection of renovascular hypertension, state of art. Ann Intern Med. 1992; 117845-853.

18. Elliott WJ,Martin WB,Murphy MB. Comparison of two noninvasive screening tests for renovascular hypertension. Arch Intern Med. 1993; 153:755-764.

19. Orellana P,Jalil R, Valdes F, Fava M, Olea E, Fernandez MS, et al. Renal scintigraphy with captopril in the evaluation of renovascular hypertension. Rev Med Chil. 1993; 121:762-767.

20. Dey HM, Hoffer PB, Lerner E, Zubal IG,Setaro JF, Black HR. Quantitative analysis of the Tc99m-DTPA captopril renogram:contribution of wash out parameters to the diagnosis of renal artery stenosis. J Nucl Med. 1993; 34:1416-1419. 
21. Majd M, potter BM, Guzzetta PC. Effects of captopril on efficacy of renal scintigraphy in detection of renal artery stenosis [Abstract]. J Nucl Med, 1983; $24: 23$.

22. Wenting GJ, Tan-Tjiong HL, Derkx FH, de Bruyn JH, Man int't Ved AJ, Schalekamp MA. Split renal function after captopril in unilateral renal artery stenosis. Br Med J (Clin Res Ed). 1984; 288:886-890.

23. Miyamori I,Yasuhara S, Tekeda Y, Koshida H, Ikeda M, Nagi K,et al. Effect of converting enzyme inhibition on split renal function in renovascular hypertension. Hypertension. 1986; 8:415421.

24. Sfakianakis GN,Bourgoignie JJ , Jaffe D, Kyriakides G, Perez-Stable E, Duncan RC. Single dose captopril scintigraphy in the diagnosis of renovascular hypertension, J Nucl Med. 1987; 28:1383-1392.

25. Fommei E, Ghione S, Palla L, Mosca F, Ferrari M, Palombo C,. et al. Renal scintigraphic captopril test in the diagnosis of renavascular hypertension. Hypertension. 1987; 10:212-220.

26. Mann SJ Pickering TG, Sos TA, Uzzo RG , Sarkar S, Friend K, et al. captopril renography in the diagnosis of renal artery stenosis : Accuracy and limitation Am J MED.1991;90:30-40.

27. Dondi M, Fanti S, DE Fabritiis A,Zuccala A, Gaggi R, Mirelli M, et al. Prognostic value of captopril renal scintigraphy in renovascular hypertension J Nucl Med. 1992;33:20402044.

28. Kumar R,Padhy AK,Machineni S, Pandey AK , Malhotra A. Individual kidney glomerular filteration rate in the interpation of non-diagnostic curves on captopril renography. Nucl. Med Commun. 2000; 21:637-643.

29. Van jaarsveld BC, Krijenen P, Derkx FH, Oei HY, Postma CT, Schalekamp MA.. The place of renal scintigraphy in the diagnosis of renal artery stenosis Fifteen years of clinical experience.Arch Intern Med. 1997; 157:1226-34.

30. Nally JV, Barton DP. Contemporary approach to diagnosis and evaluation of renovascular hypertension.Urol Clin North Am. 2001; 28:781-791.

31. Eyler WR, Clark MD, German JE, Rian RL, Meininger DE. Angiography of renal area including a comparative study of renal artery stenosis in patients with and without hypertension. Radiology 1962; 78:879-891.

32. Ergun EL, Caglar M. Tc-99m-DTPA captopril renography in the detection of renovascular hypertension due to renal polar artery stenosis. Ann Nucl Med. 2001; 15:167-170.

33. Blaufox MD, Fine EJ, Heller S, Hurley J, Jagust M, Li Y, et al. Prospective study of simultaneous Orthiodohippurate and Diethylenetriaminepentaacetic acid Captopril renography. J Nucl Med. 1998; 39:522-528. 